\title{
Application of Total Suspended Particles (TSP) analysis performed by SEM-EDS
}

\author{
Roberto Ramirez-Leal, Martin Cruz-Campas, Octavio Cota-Arriola and Daniel Morales-Romero
}

\section{Sonora State University, Hermosillo, Sonora, Mexico}

The composition of the suspended particles, in many cases, turns out to be a complex mixture of different elements and compounds, which is explained by the great variety of emission sources and by the reactivity that they usually have at the time they are generated. Studies have been carried out in various parts of the world to characterize their composition and structure, but the information available to date is not enough. [2]

TSP is generally composed of several components including resuspended soil particles, weathered materials, fly ash and vehicle-generated pollutants, and they are ubiquitous environmental pollutants that formed in building construction, combustion of coal wood and atmospheric chemical reaction. But by far, responded road dust, traffic, and other combustion processes are usually deemed to be the principal sources of TSP. Determination of the origin of TSP is often based on their morphological and chemical characteristics. So the study of TSP pollution is important. [1]

Despite having knowledge of the potential toxicity of many of the chemical substances that make up suspended particles, the morphological and chemical profiles of their emission sources and the way in which they are modified during their transit through the air are not known with certainty atmosphere, maintaining its size or adding to others to form larger particles of different morphology. [3]

TSP particles was collected by 3 high-volume samplers, located in north, downtown and northwest in the city, using a sampling flow of $1.3 \mathrm{~m} / \mathrm{min}$. Sampling was carried for $24-\mathrm{h}$ one day a week. The filters used were fiberglass, with size of $8 \times 10$ inch that captured TSP particles. Analysis of TSP were performed using scanning electron microscopy (SEM) JEOL Model JSM-5800LV coupled with energy dispersive spectrometer (EDS) EDAX DX prime brand, for determination of morphology and elemental composition of airborne particles. Specimens were processed by separating the collected particles from the fiberglass filters by means of submersing a $2 \mathrm{~cm}^{2}$ section of each filter into isopropilic alcohol within a test tube for 5 minutes. Then, an aliquot of the suspension was placed over a sample holder, and is introduced into the chamber of SEM.

The aim of the present study is to examine morphology and elemental chemical composition of single TSP particles as part of an air quality study by SEM-EDS.

The City of Hermosillo is located between latitude $20^{\circ} 01^{\prime} 00$ "and $20^{\circ} 08^{\prime} 30^{\prime \prime}$ north latitude and between the meridian $110^{\circ} 54^{\prime} 30^{\prime \prime}$ and $111^{\circ} 01^{\prime} 00^{\prime \prime}$ west longitude at an altitude of $200 \mathrm{~m}$ above sea level; is the Sonora state's capital, located to the Center-West of the coastal plain, in northwestern Mexico. [2]

The structure of particles can be diverse and they usually present a two dimensional aspect. It is found that such particles have a irregular morphology, outlying edges and fracture lines. (Fig. 1)

Based on the EDS results, the following elements were found: $\mathrm{Al}, \mathrm{Ba}, \mathrm{Ca}, \mathrm{Ce}, \mathrm{Cl}, \mathrm{Cr}, \mathrm{Cu}, \mathrm{Fe}, \mathrm{K}, \mathrm{Mg}, \mathrm{Mo}$, $\mathrm{Na}, \mathrm{Ni}, \mathrm{Pb}, \mathrm{S}, \mathrm{Si}, \mathrm{Ti}, \mathrm{W}, \mathrm{Zn}$ and $\mathrm{Zr}$; and the predominant elements were W (At\% 12.53), Na (At\% 10.87), $\mathrm{Al}$ (At\% 9.94) and Fe (At\% 9.67). (Fig. 2).

The results obtained from the characterization of the particles captured by TSP filters, showed that elements such as $\mathrm{Al}, \mathrm{Si}, \mathrm{Ca}, \mathrm{Fe}, \mathrm{K}$, and $\mathrm{Mg}$ are largely abundant, and are usually related with litophilic sources, such as agricultural activities, areas of soil free of anthropogenic impact, paved streets and 
construction sites. While elements such as $\mathrm{Cl}$ are more frequently associated with incineration and combustion activities as well as derived from marine aerosols. Other chemical elements such as $\mathrm{Ba}, \mathrm{Cu}$, $\mathrm{Cr}, \mathrm{Na}, \mathrm{Ni}, \mathrm{Pb}, \mathrm{Ti}, \mathrm{W}$ and $\mathrm{Zn}$ are more commonly related various human and industrial activities. The $\mathrm{S}$ is an indicator of fuel combustion activities and part of the regional supply of sulfate.

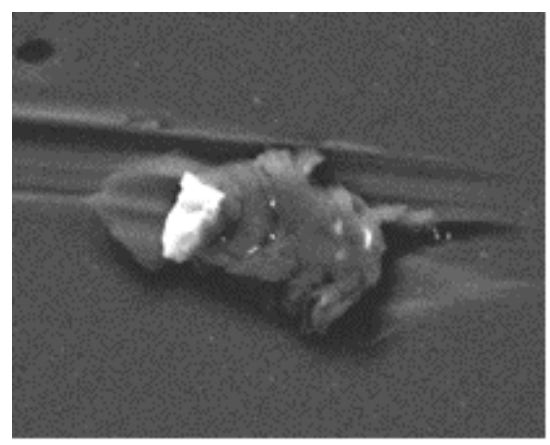

Figure 1. Micrograph of the sample in SEM-EDS. 4000x BEI and $15 \mathrm{Kv}$

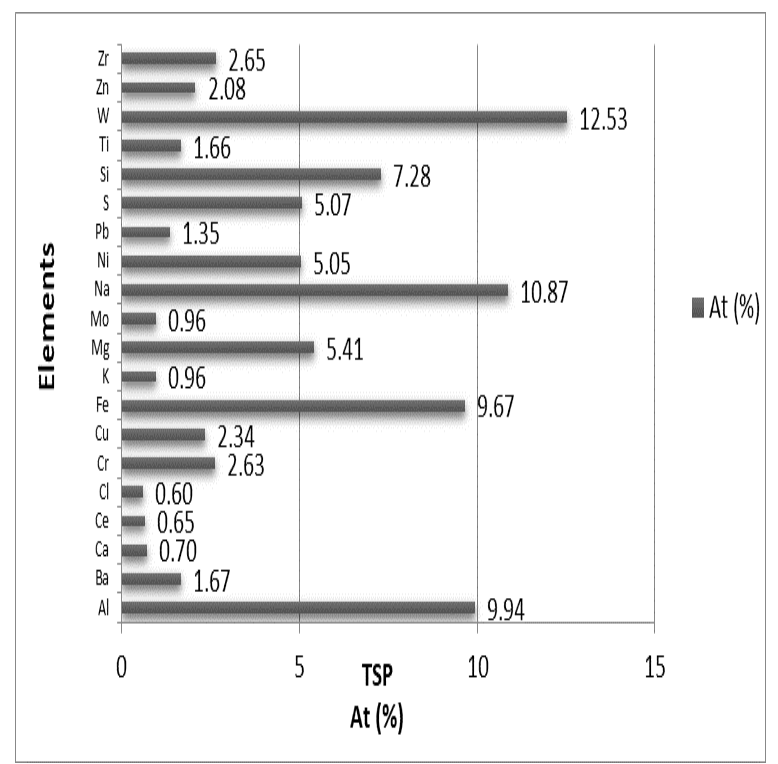

Figure 2. Majority of elemental constituents of TSP samples in city area (Averaged values of atomic percentage (At\%) for all filter samples).

\section{References}

1.- Ramirez-Leal, R., Esparza-Ponce,H and Duarte-Moller,A. (2007). Characterization of inorganic atmospheric particles in air quality program with sem, tem and xas. Revista Mexicana de Fisica 53(3): 102-107..

2.- Ramirez-Leal, R.,Valle-Martinez,M. and Cruz-Campas, M. (2014). Chemical and Morphological Study of PM10 Analysed by SEM-EDS. Open Journal of Air Pollution, 3, 121-129

3.- M. Cruz-Campas, R. Ramirez-Leal and N. Lopez-Perez. (2019). TSP Analysis Performed by SEMEDS to Air Quality Studies. Microsc. Microanal. 25 (Suppl 2) 